\title{
IFKIS - a basis for managing avalanche risk in settlements and on roads in Switzerland
}

\author{
M. Bründl ${ }^{1}$, H.-J. Etter ${ }^{1}$, M. Steiniger ${ }^{1}$, Ch. Klingler $^{2}$, J. Rhyner ${ }^{1}$, and W. J. Ammann ${ }^{1}$ \\ ${ }^{1}$ WSL Swiss Federal Institute for Snow and Avalanche Research SLF, Flüelastrasse 11, CH-7260 Davos Dorf, Switzerland \\ ${ }^{2}$ Alpine Safety and Information Centre ASI, Bruggfeldstrasse 5, A-6500 Landeck, Austria
}

Received: 29 September 2003 - Accepted: 3 March 2004 - Published: 16 April 2004

Part of Special Issue "Multidisciplinary approaches in natural hazards"

\begin{abstract}
After the avalanche winter of 1999 in Switzerland, which caused 17 deaths and damage of over CHF 600 mill. in buildings and on roads, the project IFKIS, aimed at improving the basics of organizational measures (closure of roads, evacuation etc.) in avalanche risk management, was initiated.

The three main parts of the project were the development of a compulsory checklist for avalanche safety services, a modular education and training course program and an information system for safety services. The information system was developed in order to improve both the information flux between the national centre for avalanche forecasting, the Swiss Federal Institute for Snow and Avalanche Research SLF, and the local safety services on the one hand and the communication between avalanche safety services in the communities on the other hand.

The results of this project make a valuable contribution to strengthening organizational measures in avalanche risk management and to closing the gaps, which became apparent during the avalanche winter of 1999. They are not restricted to snow avalanches but can also be adapted for dealing with other natural hazard processes and catastrophes.
\end{abstract}

\section{Introduction}

During the last few decades, the protection of villages and traffic routes against snow avalanches has been based on a combination of technical, biological and organizational measures and land-use planning. After the avalanche winter of 1950/1951, which caused 98 deaths in Switzerland, 75 of them in buildings, technical measures such as the construction of avalanche barriers in the starting zones, were the main focus of efforts to protect exposed villages against avalanches. To date around CHF 1.5 billion has been invested in this kind of avalanche protection. Starting in the 1960s, the concept of hazard maps that subdivide avalanche threatened

Correspondence to: $\mathrm{M}$. Bründl

(bruendl@slf.ch) areas into red zones (high pressure and/or frequently endangered), blue zones (less pressure and less frequently endangered) and white zones (no apparent danger) were developed and introduced in almost all villages which can be affected by avalanches.

Particularly in recent years, organizational measures, such as artificial avalanche release, closure of traffic routes and evacuation, have become more and more important. Essential elements that form the basics of organizational measures include avalanche forecasting, early warning systems, measurements, data produced by modelling, and observations from the terrain. To improve these basics, the framework "Avalanche Warning CH 2000" (Russi et al., 1998) was initiated and successfully completed. The main results of this effort are a network of automatic stations for the measurement of meteorological and snow parameters and an internet based information platform for safety services. Moreover the development of physically (Bartelt and Lehning, 2002; Lehning et al., 2002a, 2002b) and statistically based (Brabec, 2002) snowpack and forecast models has been enforced.

During January and February 1999, these improvements had to face their first hard test. From 27 January to 25 February 1999 , three precipitation periods brought over $5 \mathrm{~m}$ of new snow to the Swiss Alps, resulting in 1350 destructive avalanches, 17 deaths and damage of over CHF 600 mill. in buildings and on roads (Wilhelm et al., 2000). The event analysis showed that the concept of integral avalanche protection had worked well. However, in the field of organizational measures, some deficiencies became apparent on the part of the safety services and in their performance in crisis management. The crucial points are that tasks should be well defined, that the safety services should be well trained, and that there should be an efficient information flow between the national warning service and the safety services and between those responsible for safety in villages, in tourist facilities and on traffic routes.

These deficiencies were approached in the project "Intercantonal Early Warning and Crisis Information System" ("Interkantonales Frühwarn- und Kriseninformations- 
Table 1. The principal goals of the SLF course program for avalanche experts. In addition to the general part, Course A contains 3 modules for further specialisation. Course B has no additional modules.

\begin{tabular}{|c|c|c|}
\hline & Level A & Level B \\
\hline \multirow[t]{4}{*}{ Basic part } & $\begin{array}{l}\text { Weather: Knowledge of the generally available meteorologi- } \\
\text { cal information and ability to interpret this in view of the } \\
\text { avalanche danger. }\end{array}$ & $\begin{array}{l}\text { Weather: Same as level A, but in addition ability to interpret } \\
\text { synoptic maps. } \\
\text { - Ability to use and interpret the InfoBox and observer data. }\end{array}$ \\
\hline & $\begin{array}{l}\text { Snow: Knowledge of the basic snow forms and the most } \\
\text { important parameters influencing snowpack stability. } \\
\text { - Ability to make snow profiles and interpret the correspon- } \\
\text { ding snow profile plot. }\end{array}$ & $\begin{array}{l}\text { Snow: Knowledge of the basic snow forms and the most } \\
\text { important parameters influencing snowpack stability. } \\
\text { - Ability to interpret snow profiles. }\end{array}$ \\
\hline & $\begin{array}{l}\text { Avalanche danger: Knowledge of all SLF information and } \\
\text { ability to interpret this in accordance with individual needs. } \\
\text { Knowledge of the factors responsible for avalanche forma- } \\
\text { tion and ability to estimate the actual local avalanche danger. }\end{array}$ & $\begin{array}{l}\text { Avalanche danger: Knowledge of all SLF information, } \\
\text { concerning the InfoBox, and ability to draw the appropriate } \\
\text { conclusions. }\end{array}$ \\
\hline & & $\begin{array}{l}\text { Measures: Ability to estimate the actual risk potential by } \\
\text { using the danger map. } \\
\text { Knowledge of the artificial release methods, advantages, } \\
\text { disadvantages, and the legal situation. } \\
\text { - Ability to recommend appropriate measures. }\end{array}$ \\
\hline $\begin{array}{l}\text { Module } 1 \\
\text { (Course A) }\end{array}$ & $\begin{array}{l}\text { - Ability to compile correct data, including flat field profile, } \\
\text { and internet transfer to SLF. } \\
\text { - Ability to estimate the local avalanche danger level. }\end{array}$ & \\
\hline $\begin{array}{l}\text { Module } 2 \\
\text { (Course A) }\end{array}$ & $\begin{array}{l}\text { - Ability to make a slope profile and to use the results to } \\
\text { estimate danger level. } \\
\text { - Ability to extract the relevant information for the SLF } \\
\text { warning service. } \\
\text { - Ability to give basic instructions to beginners. }\end{array}$ & \\
\hline $\begin{array}{l}\text { Module } 3 \\
\text { (Course A) }\end{array}$ & $\begin{array}{l}\text { - Knowledge of protection measures. } \\
\text { - Ability to recognize need of organisational measures } \\
\text { and their documentation. }\end{array}$ & \\
\hline
\end{tabular}

system"), carried out by the Swiss Federal Institute for Snow and Avalanche SLF at the request of the Swiss Forest Agency BUWAL. The results of this project with regard to avalanche risk management are presented in this paper.

In the first part of the paper, we give an overview of the topics that are included in a compulsory booklet for safety services responsible for villages or traffic routes. In the second part, the education and training programme for members of these safety services is described, and the third part presents the information and communication system.

\section{The tasks of safety services}

In all the municipalities in Switzerland where avalanches can occur, one or more avalanche safety services are in charge of the safety of houses, streets and tourist facilities. Depending on the size of the municipality, the responsibility is divided among several organizations. In Davos, in the canton of Grisons for example, the tourist board is responsible for safety on cross-country skiing tracks and winter trails, the cable-car companies are responsible for safety on ski slopes, and the safety service of the municipality is in charge of safety in houses and on the streets. For safety on roads between villages, the cantonal highway department is responsible, and for railways, the regional railway company. The main task of all these services is the continuous observation of the snow and avalanche situation in their control area and the decision on appropriate measures.

The event analysis of the avalanche winter showed that requirement specifications for these tasks are not in use in all municipalities. Based on existing examples taken from several communities, we developed a checklist for a compulsory booklet as the basis for a version adapted to local needs. The following points are included:

- Purpose and definition of the area.

- Tasks: measurements, observation of the avalanche situation and data transmission to the regional or national centre, preparedness, maintenance of all equipment, implementation of safety measures such as artificial avalanche release, closures or evacuations, collaboration with rescue teams, continuous education and training. 
- Organization: constitution and organizational diagram of the service, election of the members, subdivision into departments like leadership, observation, warning and forecasting, information and public relations, rescue.

- Responsibility and spheres of competence of the members and of the leadership.

- Liability and insurance.

- Costs and finances.

- Validity: time period in which the compulsory booklet is valid.

This checklist should guarantee that the requirement specifications of all avalanche safety services in Switzerland contain this minimal set of requirements. This ensures that the work of all safety services has the same basis, which is an essential prerequisite for equal safety in villages and on roads.

Another crucial point is the educational level of those responsible for safety. To achieve the required level, an education and training programme has been developed.

\section{Education and training programme}

A two-level system of courses is offered by SLF for safety services:

Level A courses are addressed to members of safety services whose task it is to prepare information for decision makers. Level B courses are addressed to people in leadership position within safety services and from the local authorities (decision makers).

Both the A and B level courses contain a basic part. In addition, the level A course is split into three modules for subsequent specialisation. These are:

Module 1: Snow and avalanche observation.

Module 2: Estimation of the local avalanche danger (digging of snow profiles on slopes, transmission of data, etc.).

Module 3: Estimation of the risk for objects (housing, traffic routes, etc.).

The main goals of the courses are summarized in Table 1.

The courses are held according to need, usually at the beginning of winter. Very positive experience has been obtained during the last three years.

\section{Information system}

The third prerequisite for effective and efficient organizational measures to manage avalanche risk in villages and on roads is up-to-date, precise and temporally as well as spatially, highly resolved weather and snow data combined with well coordinated safety measures based on good communication between the organizations involved. The information system IFKIS addresses two directions of information flow (Fig. 1):

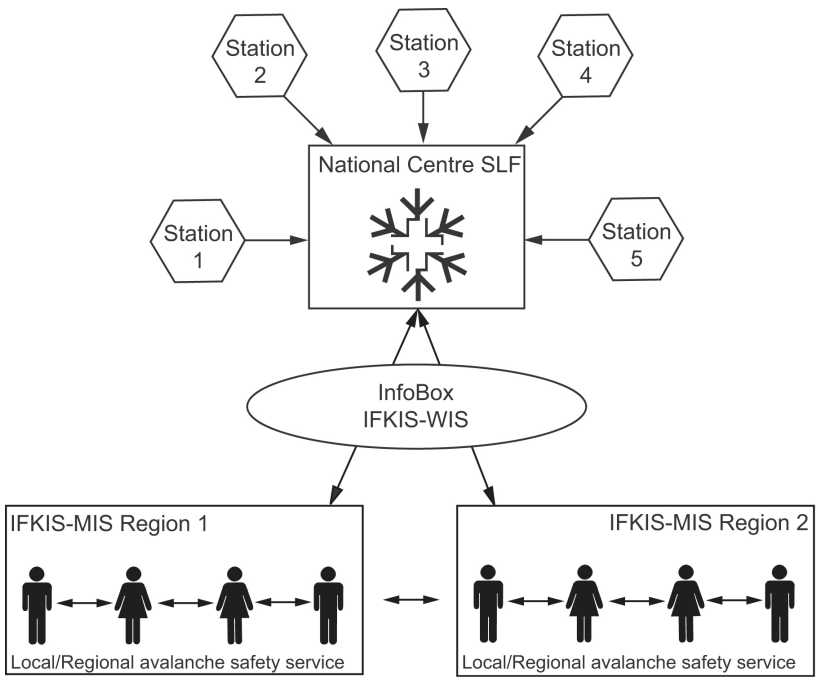

Fig. 1. Measurements and observation data are collected at the National Centre at SLF in Davos. The information system for avalanche warning (InfoBox/IFKIS-WIS) supports the vertical, bi-directional information flow from SLF to the local and regional safety services and the "measures-information system" (IFKIS-MIS), the horizontal information and communication paths for crisis management between those responsible at a local level.

- Information from the national centre to the safety services (vertical information, warning information system WIS).

- Information and communication flow between the safety services (horizontal information, measures information system MIS).

\subsection{Warning information system}

The basic information for safety services is the national ("evening") avalanche bulletin issued by SLF daily at $5 \mathrm{pm}$ and broadcast via radio, phone, fax, a series of newspapers, and the internet. This evening bulletin is completed with regionally resolved ("morning") bulletins at 8 am (Rhyner et al., 2002).

The data compiled by the automatic weather station network IMIS can be downloaded by authorized users using a Java application within the IFKIS information system. The temporal development of the data is visualized with the software tool InfoBox, which is available to nearly all safety services (Russi et al., 1998). Data which are not directly measurable, such as, for example, the amount of new snow, are modelled by the physical snowpack model SNOWPACK (Bartelt and Lehning, 2002; Lehning et al., 2002a, 2002b) using input data of the IMIS stations. The results are visualized with the information platform InfoBox. These hourly data from the avalanche release zones are important for decisions made by the safety services.

When a critical avalanche situation is imminent, an early warning message is released via the InfoBox, indicating the 


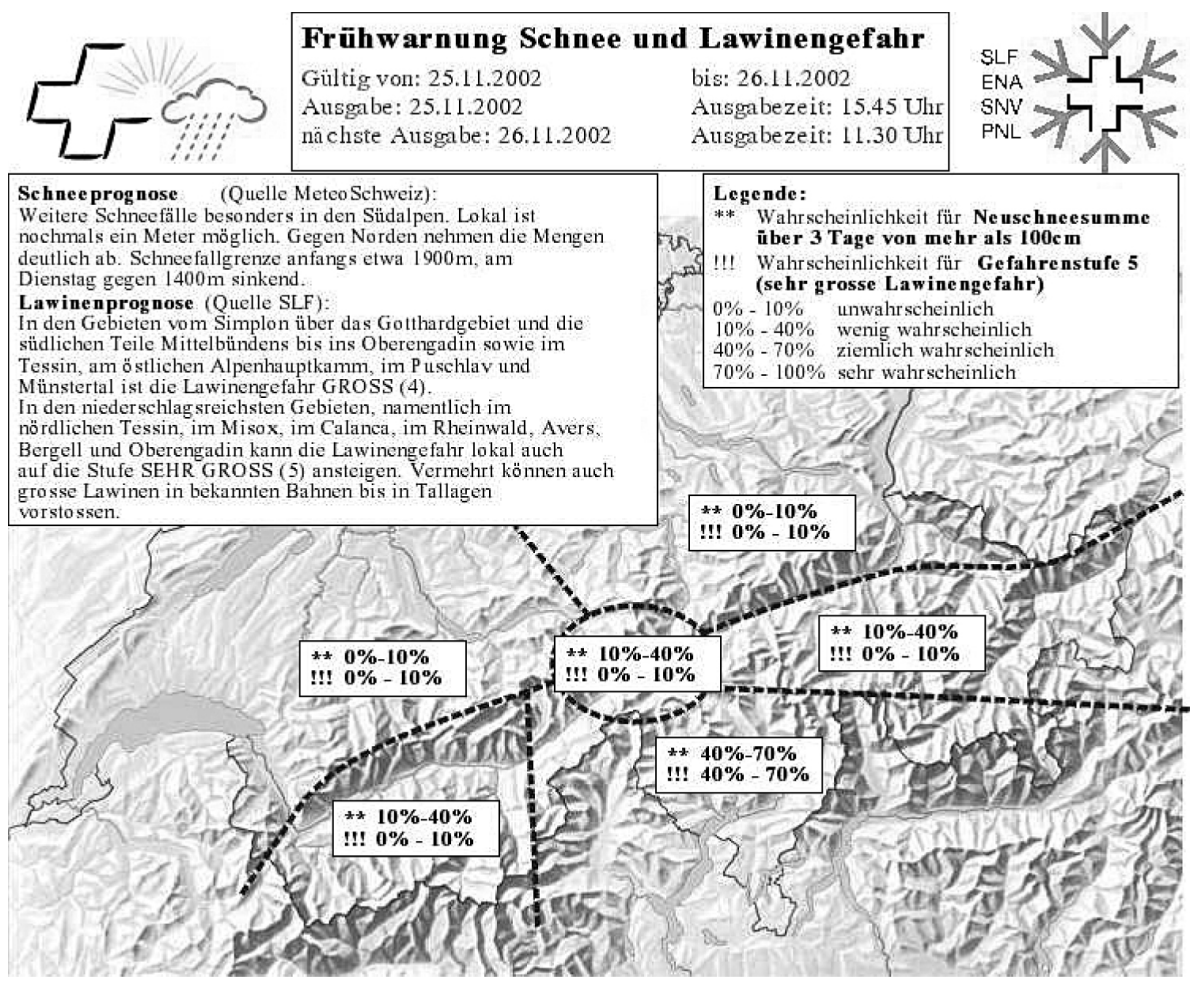

Fig. 2. Example of a map showing an "Early warning Snow and Avalanches" for safety services. critical regions (Fig. 2). This early warning is only issued when there is a high probability that the next $72 \mathrm{~h}$ will bring at least $1 \mathrm{~m}$ of new snow and that the avalanche danger will increase to level 5 ("very large", the highest level). If a heavy snowfall without avalanche danger level 5 is predicted, then an "Information Heavy Snow Fall" is issued. This information is accompanied by an SMS and/or pager alert addressing safety services with a request to consult the InfoBox. Receiving this early warning enable safety services to prepare themselves for an upcoming critical avalanche situation.

Over 100 users used the warning information system during the winter of 2001/2002 and the winter of 2002/03. The easy-to-use interface provides the possibility to gain all necessary information for decision making of avalanche safety services. The functionality of this system will be expanded in the forthcoming years. It is intended to include further data sources, which are relevant for the management of other natural hazard processes.

\subsection{Measures information system}

Efficient crisis management for villages and traffic routes requires good coordination between the safety services involved. In many cases, there are several organizations responsible for the safety in the different fields, whose decisions have to be taken jointly. The most widespread means of communication, the telephone, is not always the optimal way, since both parties have to be available simultaneously. Bringing all parties up to the same information level in a hectic situation takes too many telephone calls and therefore too much time.
In collaboration with the Alpine Safety and Information Centre ASI in Landeck, Austria, SLF developed an Internet platform, which provides all the safety services involved with the means to enter their decisions into a computer system. The system, called IFKIS-MIS ("measures information system") is based on a Content-Management System, which allows the publication of electronic data in several digital formats. The data input is easy, making it accessible also to less experienced computer users. The access to this system is password-protected, and, at present, not available to the public. The information system is divided into two parts: a "read-only" part and another part for data input ("write access"). This allows a selective allocation of "read" and/or "write" access to different groups of people. The "write" access is also divided between the different organizations by means of different passwords so that every organization is responsible for their own content. The "read-only" part, which also contains frequently used telephone lists and other specific documents, is shown in the form of a screen shot in Fig. 3.

Messages in the system lose their value if the user can't take note of them in cases of absence from their computer terminals. Therefore, an embedded alert system sends an SMS or an e-mail automatically as soon as a new message is saved by the system. In this way, the user is informed rapidly about new messages.

The information system was introduced on a test basis in the region Davos/Klosters in the canton of Grisons in February 2002. For the winter of $2002 / 2003$, the test in Davos/Klosters was extended. The region Bernese Oberland 


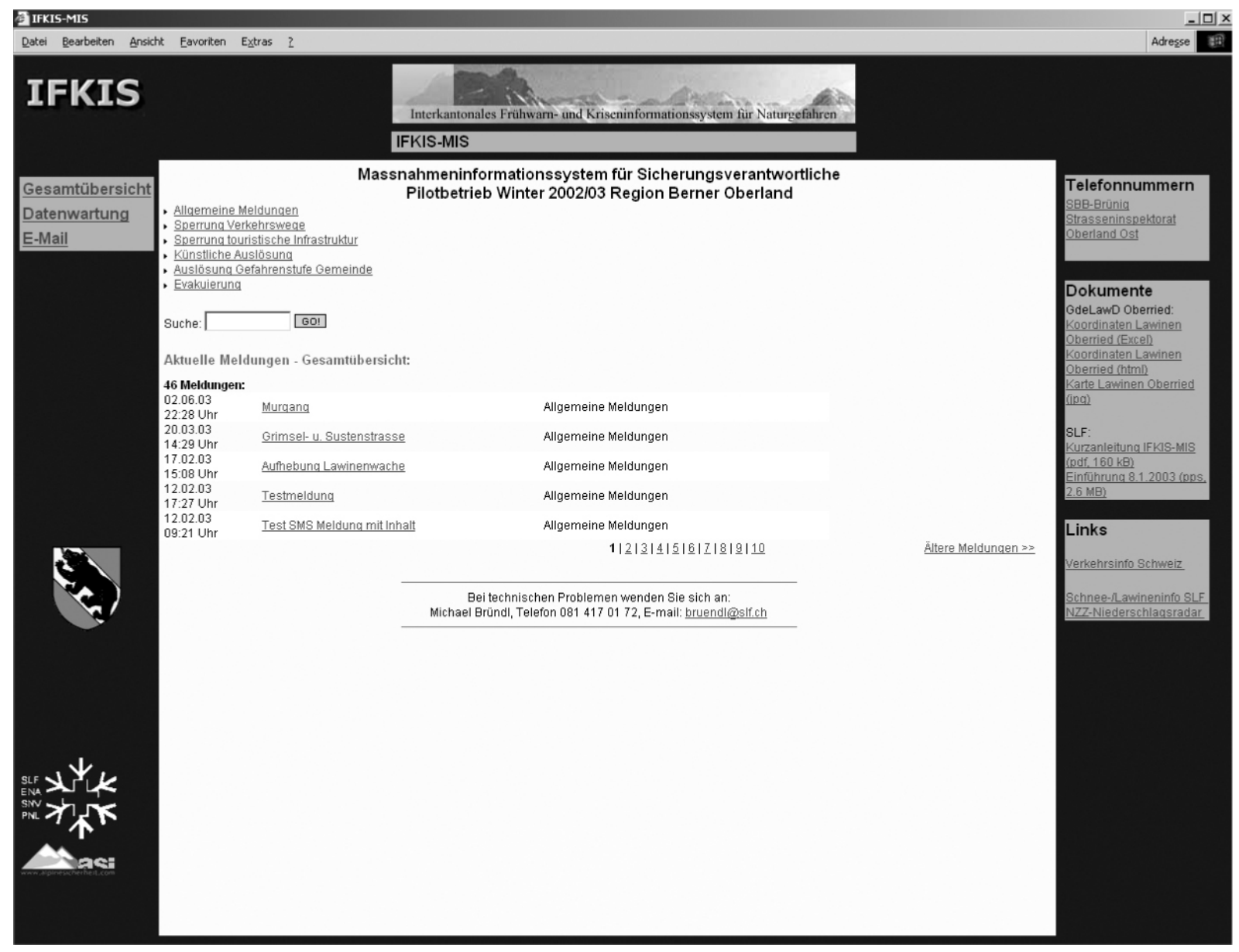

Fig. 3. Screen shot of the "read-only" part of the measures information system IFKIS-MIS.

joined this project in January 2003 and the canton of Glarus in February 2003.

\subsection{Experiences with the measures information system IFKIS-MIS}

The first practical experience was gained during a critical avalanche situation between the end of January and beginning of February 2003, especially in the Bernese Oberland. The avalanche situation became more acute because the highway A8 from Brienz to Interlaken was closed on 4 January 2003 due to rock fall. The traffic was diverted over the northern shore of the lake of Brienz, which is highly exposed to avalanches. When the avalanche danger rose to level four ("high") on 30 January, the road, the railway and several villages along the lake were increasingly endangered.

Three different organizations are responsible for the safety on roads, railways and in villages. Communication between these organizations during the avalanche situation was supported by IFKIS-MIS, which was the first practical experience of the system. The cantonal department for natural hazards also used the up-to-date information to gain a rapid overview of the situation. A comparison of the evaluation of the avalanche danger in this area with the number of mes- sages entered in IFKIS-MIS reveals an increasing number of measures parallel to the increasing avalanche danger (Fig. 4) but with a time lag of one day. The highest number of messages is registered during the phase of the greatest avalanche activity, from 4-6 February. Careful analysis of this situation shows that IFKIS-MIS performed very well. The feedback given by the users confirmed the usefulness of the system. It gave all the organizations involved the chance to remain on the same information level at any time and to coordinate safety measures with each other.

\section{Conclusions}

Organizational measures as a part of risk management practices for alpine natural hazards have become important in the last years and will become increasingly important in the future. One of the future demands will be a minimum closure (or evacuation) time, with a maximum amount of safety. This ambitious demand can only be fulfilled by making a concerted improvement in the levels of preparedness of the safety services and in their educational level. The right measure at the right time will be the desired aim in every critical situation. This can only be achieved when those 


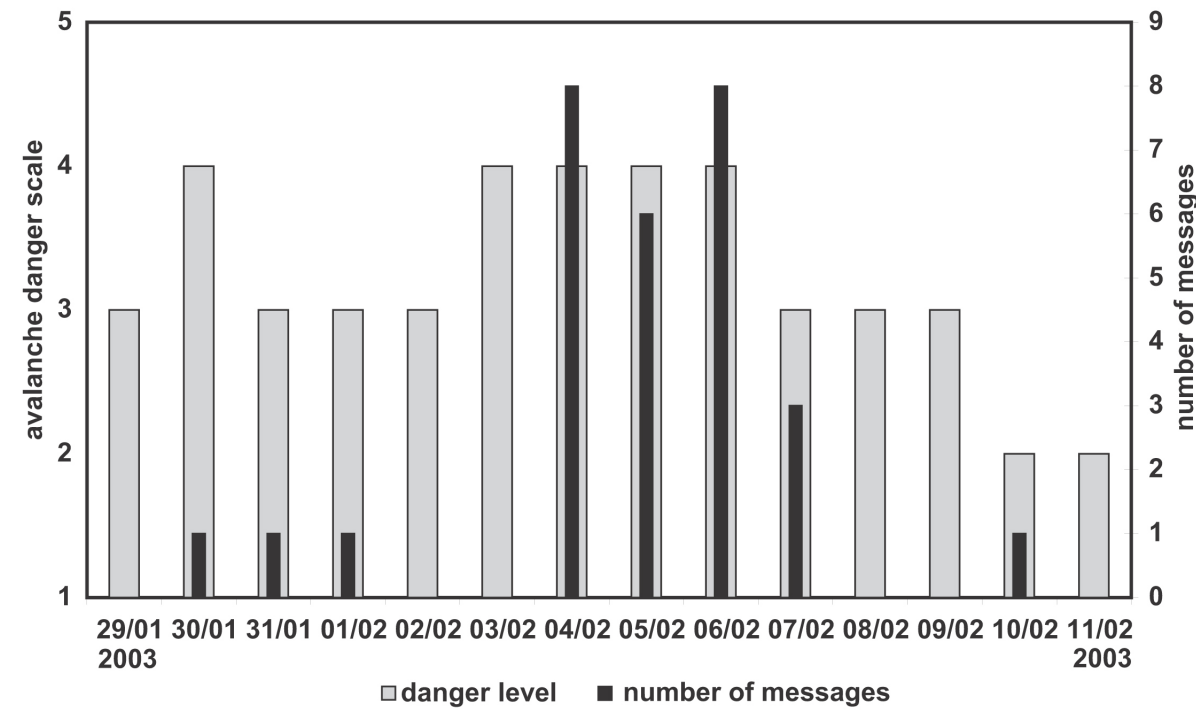

Fig. 4. Comparison between danger level and number of messages in IFKISMIS for the region Bernese Oberland from 29 January to 11 February 2003. responsible are informed in time and when they are able to decide on and to take the right measures.

An internet-based mutual information exchange is another essential requirement because it allows that all parties involved in crisis management are on the same information level. It is obvious that organizational measures cannot replace technical and biological measures (reforestation) or land-use planning, but in terms of an optimal cost-benefit ratio, they will acquire more and more importance, not only in the field of snow avalanches but for the risk management of all natural hazards.

Acknowledgements. We thank the Swiss Forest Agency for the financial support of this project.

Edited by: T. Glade

Reviewed by: two referees

\section{References}

Bartelt, P. and Lehning, M.: A physical SNOWPACK model for the Swiss avalanche warning; Part I: numerical model, Cold Reg. Sci. and Technol., 35(3), 123-145, 2002.

Brabec, B.: Computergestützte Regionale Lawinenprognose, Swiss Federal Institute of Technology Zürich, ETH-Diss Nr. 14232, Davos, 2002.

Lehning, M., Bartelt, P. B., Brown, R. L., Fierz, C., and Satyawali, P.: A physical SNOWPACK model for the Swiss Avalanche Warning Services, Part III: Meteorological Boundary Conditions, Thin Layer Formation and Evaluation, Cold Reg. Sci. Technol., 35, 169-184, 2002a.

Lehning, M., Bartelt, P., Brown, B., Fierz, C., and Satyawali, P.: A physical SNOWPACK model for the Swiss avalanche warning, Part II: Snow microstructure, Cold Reg. Sci. and Technol., 35(3), 147-167, 2002b.

Rhyner, J., Bründl, M., Etter, H.-J., Steiniger, M., Stöckli, U., Stucki, Th., Zimmerli, M., and Ammann, W.: Avalanche Warning Switzerland - Consequences of the avalanche winter 1999, Proceedings of the 13th International Snow Science Workshop, Penticton, B.C., Canada, 2002.

Russi, T., Ammann, W., Brabec, B., Lehning, M., and Meister, R.: Avalanche Warning Switzerland 2000, Proceedings of the 11th International Snow Science Workshop, Sunriver, Oregon, USA, 1998.

Wilhelm, Ch., Wiesinger, Th., Bründl, M., and Ammann, W.: The avalanche winter 1999 in Switzerland - an overview, Proceedings of the 12th International Snow Science Workshop, Big Sky, Montana, USA, 2000. 